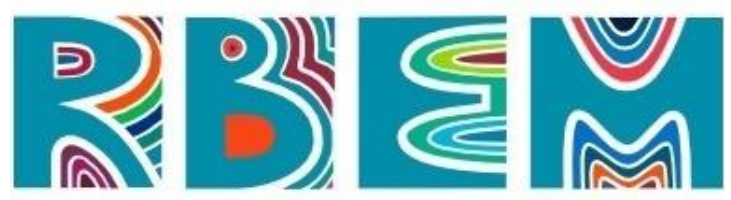

REVISTA BAIANA DE EDUCAÇÃO MATEMÁTICA

ARTIGO

do1 https://doi.org/10.47207/rbem.v1i.10296

\title{
MANCALA: o uso do jogo como recurso educacional
}

\author{
SOUZA, Claudio Henrique Sales de \\ Pontifícia Universidade Católica (PUC-Rio). Es pecialista em Educação Matemática pelo Colégio Pedro II \\ (CPII). ORCID: https://orcid.org/0000-0002-3140-5815. E-mail: claudiohenrique28@gmail.com. \\ COSTA, Liliana Manuela Gaspar Cerveira da \\ Colégio Pedro II/NEPEM (CPII). Doutora em Matemática pela Universidade de Aveiro, Portugal. ORCID: \\ https://orcid.org/0000-0002-5258-1447. E-mail: imgccosta@gmail.com.
}

\begin{abstract}
Resumo: O objetivo deste trabalho é apresentar as potencialidades didáticas do jogo africano Mancala no ensino de Matemática ao nível do Ensino Fundamental. Será análisado como o uso de jogos é abordado nos Parâmetros Curriculares Nacionais, na Base Nacional Comum Curricular e por pesquisadores que escreveram sobre este assunto. Também serão discutidos alguns tópicos matemáticos que foram explorados em uma atividade aplicada em duas turmas do $7^{\circ}$ ano do Ensino Fundamental de uma escola da rede privada, onde os alunos responderam um questionário no decorrer do jogo. Através das respostas dadas pelos alunos, será discutido o potencial didático-pedagógico do Mancala, chegando à conclusão da existência de diversas potencialidades do mesmo. O presente trabalho é uma pequisa qualitativa de caráter exploratório, que foi antecedida por uma pesquisa bibliográfica.

Palavras-chave: Jogo. Mancala. Recurso didático.
\end{abstract}

\section{MANCALA: the use of game as an educational resource}

Abstract: The purpose of this paper is to present the didactic potentialities of the African game Mancala in the teaching of Mathematics at Elementary Education. It will be analyzed how the use of games is addressed in the National Curriculum Parameters, in the National Common Curricular Base, and by some researchers who have written on this subject. Some mathematical topics, which were explored in an applied activity in classes of the 7th grade, will also be discussed. This work is qualitative research with an exploratory character, which was preceded by bibliographic research.

Keywords: Game. Mancala. Educational resource.

\section{MANCALA: el uso del juego como recurso educativo}

Resumen: El objetivo de este trabajo es presentar las potencialidades didácticas del juego africano Mancala en la enseñanza de las Matemáticas a nivel de Educación Primaria. Se analizará cómo se aborda el uso de juegos en los Parámetros Curriculares Nacionales, en la Base Curricular Común Nacional y por investigadores que han escrito sobre este tema. También se discutirán algunos temas matemáticos, los cuales fueron explorados en una actividad aplicada en dos clases del $7^{\circ}$ grado de la Escuela Primaria en un colegio privado, donde los estudiantes respondieron un cuestionario durante el juego. 


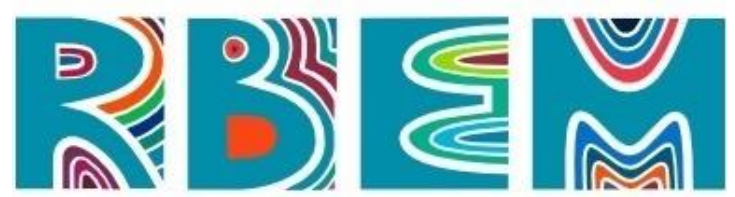

REVISTA BAIANA DE EDUCAÇÃO MATEMÁTICA

A través de las respuestas dadas por los estudiantes, se discutirá el potencial didáctico y pedagógico de Mancala, llegando a la conclusión de la existencia de varias potencialidades del mismo. El presente trabajo es una investigación cualitativa de carácter exploratorio, que fue precedida por una investigación bibliográfica.

Palavras-Clave: Juego. Mancala Recurso educativo.

\section{Introdução}

São muitos os textos que tratam sobre a utilização de jogos como recurso didático na aula de Matemática, alguns observando os jogos de forma mais teórica e conceitual, outros analisando a forma prática de sua utilização enquanto instrumento na atividade letiva.

O presente trabalho resulta do Trabalho de Conclusão de Curso de um dos autores e teve uma prévia apresentada no SPEM $2020^{1}$, e nele se busca compreender a função do jogo em sala de aula, tendo como base os documentos oficiais que norteiam a Educação Básica (EB) brasileira, nomeadamente os Parâmetros Curriculares Nacionais (PCN) e a Base Nacional Comum Curricular (BNCC), além de destacar alguns autores de que se debruçaram sobre este tema.

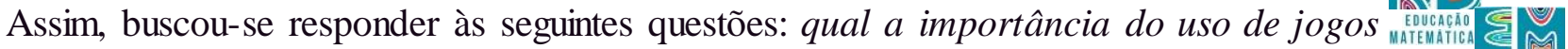
como recurso pedagógico? Existe essa necessidade à luz dos documentos oficiais e à luz dos pesquisadores?

A nossa escolha recaiu sobre o jogo Africano Mancala que foi usado na elaboração de uma atividade destinada ao $7^{\circ}$ ano do Ensino Fundamental, da qual consta um questionário em que se exploram alguns conceitos e que serviu para coleta de dados, permitindo verificar como os alunos lidam com essas mesmas questões quando estas são colocadas no desenvolvimento do jogo, que passa a ser visto como material concreto.

De forma mais específica, surgiram outras questões: quais são as potencialidades didáticas do Mancala? É possível explorar essas potencialidades no Ensino Fundamental?

Isto posto, esse trabalho teve como objetivo explorar as vantagens decorrentes do uso de jogos na aula de Matemática, em particular dos jogos da família Mancala, elaborando um questionário baseado em temas de matemáticos que se adequam com a mecânica do jogo.

\footnotetext{
${ }^{1}$ SPEM 2020 IX Seminário de Pesquisa em Educação Matemática do Rio de Janeiro
} 


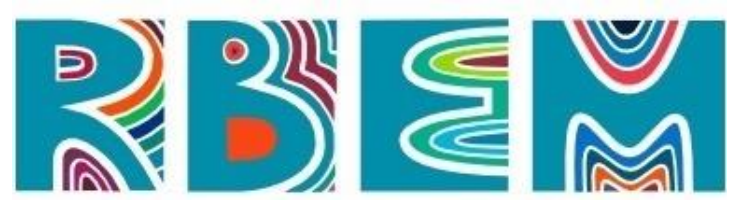

\section{O jogo como recurso didático}

A utilização de jogos como recurso didático na aula de Matemática é vista como uma ferramenta capaz de tornar os conteúdos matemáticos mais acessíveis ao aluno. Essa visão é corroborada por alguns autores, dos quais destacamos Barreto e Freitas (2016), Santos (2008) e também pelos documentos oficiais, de forma direta nos Parâmetros Curriculares Nacionais (PCN) e de forma mais tímida na Base Nacional Comum Curricular (BNCC).

\section{O jogo como recurso didático nos documentos oficiais}

Ao comparar as propostas feitas nos PCN e na BNCC, nota-se um retrocesso na orientação dada aos professores de Matemática no que se refere ao uso de jogos como recurso didático. Nos primeiros, se encontra no tópico: "Alguns caminhos para fazer "Matemática" na sala de aula" (BRASIL, 1998, p. 42) o subtópico "O RECURSO AOS JOGOS” (p. 46) em que é feita uma referência explícita aos jogos como um instrumento motivador para a colocação de problemas de modo atrativo, que favorece a criatividade na elaboração de estratégias de resolução e busca de soluções dos mesmos. Assim, o jogo, aliando o seu caráter lúdico à sua diversidade, permite despertar no aluno a curiosidade, levando-o a refletir sobre as situações apresentadas e, também, contribuir no "desenvolvimento dos processos psicológicos básicos; supõe um fazer sem obrigação externa e imposta, embora demande exigências, normas e controle.’(p.47)

Um outro aspecto a ressaltar é a contribuição que a prática do jogo em sala de aula pode dar na formação de valores e atitudes dos estudantes, contribuindo para o "desenvolvimento da crítica, da intuição, da criação de estratégias e da possibilidade de alterálas quando o resultado não é satisfatório - necessárias para aprendizagem da Matemática"(p. 47).

Além do que já foi referido, o jogo propicia, também, “a construção de uma atitude positiva perante os erros, uma vez que as situações sucedem-se rapidamente e podem ser corrigidas de forma natural, no decorrer da ação, sem deixar marcas negativas" (BRASIL, 1998, p. 46). O erro tem sido amplamente estigmatizado no ambiente escolar, em especial na 


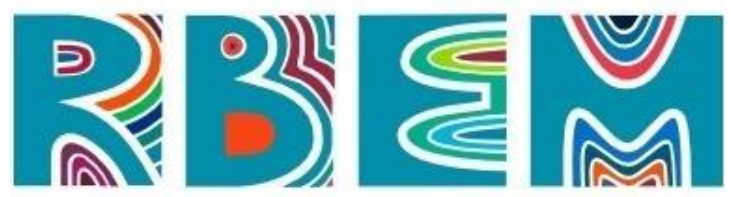

REVISTA BAIANA DE EDUCAÇÃO MATEMÁtICA

aula de Matemática, contrariando as recentes correntes pedagógicas fundamentadas na neurociência. Segundo Boaler (2020, p. 37), "Os momentos em que estamos enfrentando dificuldades e cometendo erros são os melhores momentos para crescimento cerebral". Assim, o jogo possibilita ao aluno um aprendizado dinâmico com base, não só nos seus acertos, mas também em seus erros, em que “ muitas vezes, o critério de certo ou errado é decidido pelo grupo. Assim, a prática do debate permite o exercício da argumentação e a organização do pensamento" (BRASIL, 1998, p. 46).

Ainda segundo os PCN, as atividades de jogos propiciam a análise e avaliação dos seguintes aspectos:

- compreensão: tanto no entendimento do processo do jogo em si, assim como no auto-conhecimento no que concerne ao autocontrole e ao respeito a si próprio;

- facilidade: na construção de estratégias vencedoras;

- capacidade de comunicação: no que respeita a procedimentos a serem seguidos e a formas de atuação;

- estratégia utilizada: capacidade de comparar com as previsões ou hipóteses.

Em um jogo, pode ocorrer flexibilização das regras, mudando o conceito de certo e errado em cada situação, fazendo com que o aluno tenha de adaptar ou alterar suas estratégias. O uso de jogos auxilia, também, no desenvolvimento da autonomia do aluno e na construção do pensamento crítico.

O jogo pode ser individual ou em grupo, sendo que a participação neste último "representa uma conquista cognitiva, emocional, moral e social para o estudante e um estímulo para o desenvolvimento de sua competência matemática.” (BRASIL, 1998, p. 47)

É de especial importância o fato de existir, no decurso do jogo, uma troca de papéis, tanto do professor quanto do aluno. O primeiro passa de detentor do saber para mediador entre o objeto do conhecimento e o aluno. O aluno passa de mero espectador para protagonista no processo de aprendizagem e da construção significativa do conhecimento, tendo autonomia para elaborar conjecturas que vão sendo por ele testadas no decorrer do próprio jogo. 


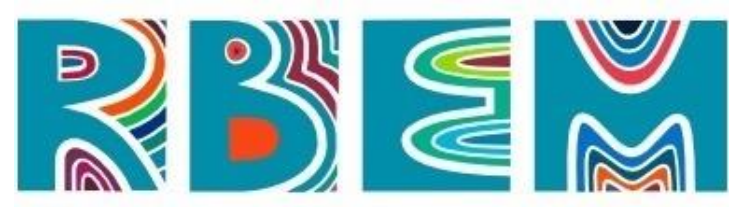

REVISTA BAIANA dE EDUCAÇÃo MATEMÁtICA

Por mais que na BNCC não seja falado diretamente sobre o uso de jogos na aula de Matemática, o jogo ajuda a fazer com que se cumpra o que é ali proposto. Nomeadamente, na quarta competência específica de Matemática para o Ensino Fundamental da BNCC, se diz

Fazer observações sistemáticas de aspectos quantitativos e qualitativos presentes nas práticas sociais e culturais, de modo a investigar, organizar, representar e comunicar informações relevantes, para interpretá-las e avaliálas crítica e eticamente, produzindo argumentos convincentes.(BRASIL, 2018, p. 297)

Por isso, o professor não deve abrir mão deste recurso. Também, quanto aos recursos didáticos, é feito um importante alerta na BNCC: "esses recursos e materiais precisam estar integrados a situações que propiciem a reflexão, contribuindo para a sistematização e a formalização dos conceitos matemáticos.” (BRASIL, 2018, p. 298)

Nenhum recurso didático deve ser utilizado como mero entretenimento. Falando especificamente sobre o uso de jogos, existe o risco de uma atividade se desvirtuar de sua intenção se os objetivos de sua utilização não estiverem bem claros. Qualquer jogo, ao ser aplicado em sala de aula, deve estar associado a uma atividade que leve o aluno a refletir ou a aprender assuntos relacionados aos objetivos da aula.

\section{Quadro teórico}

Em consonância ao atrás referido sobre a mudança do papel do professor, quando ocorre o uso do jogo, Barreto e Freitas (2016) concluiram que ao utilizar jogos em sala de aula:

o papel do professor muda de comunicador de conhecimento para o de problematizador, observador, facilitador, mediador e incentivador da aprendizagem, no processo de construção do saber pelo aluno (p. 149)

O aluno vira protagonista dentro da sala de aula, estabelecendo uma relação de maior confiança com seu professor, que ficando mais acessível ao seu aluno, facilita a comunicação e o processo de ensino-aprendizagem.

A importância de brincar é ressaltada por Machado (1994, p. 28, apud Malfato, 2012, p. 4): "brincar é, para a criança pequena, o que trabalhar deveria ser para o adulto: fonte de auto-descoberta, prazer e crescimento". O uso de jogos, que para as crianças e pré- 


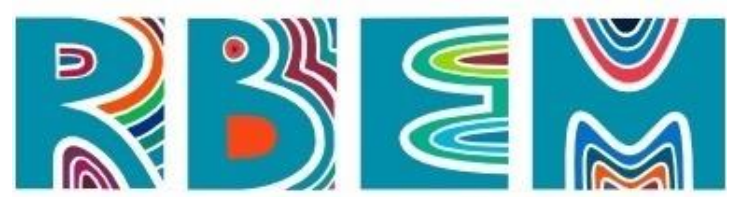

REVISTA BAIANA DE EDUCAÇÃO MATEMÁtICA

adolescentes pode ser visto como uma brincadeira, é na verdade uma necessidade. Já, para o docente, deve ser visto como uma oportunidade de, através de uma abordagem lúdica, chegar aos objetivos pré-estabelecidos de aprendizagem. É mais que possível, é necessário, no ensino fundamental, que se aprenda brincando.

Segundo Moura (1992, p.47), o ato de ensinar pressupõe a existência de determinados objetivos, o que por sua vez vai determinar a necessidade de intencionalidade nas escolhas efetuadas. Assim, ao usar o jogo como recurso de ensino, "o professor o faz com uma intenção: propiciar a aprendizagem. $\mathrm{E}$ ao fazer isto tem como propósito o ensino de um conteúdo ou de uma habilidade. Dessa forma, o jogo escolhido deverá permitir o cumprimento deste objetivo."

Deve tomar-se particular cuidado para que a utilização de jogos não ocorra sem que seja feito previamente um planejamento adequado. Segundo Petty (1995, p. 11, apud Barreto, Freitas, 2016, p. 148):

Jogar é uma das atividades em que a criança pode agir e produzir seus próprios conhecimentos. No entanto, nossa proposta não é substituir as atividades em sala de aula por situações de jogos. (...) a ideia será sempre

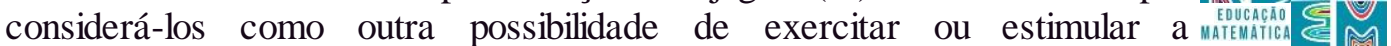
construção de conceitos e noções também exigidos para a realização de tarefas escolares.

Usar jogos fora do propósito de adequar um conteúdo ao aluno, pode ter efeito contrário ao esperado, sendo prejudicial ao aprendizado e, o jogo por si só, não irá trazer o interesse do aluno pelo conteúdo. Porém, ao fazer articulações entre as mecânicas do jogo e os tópicos matemáticos que desejam ser aprendidos, o aluno pode obter ganhos inestimáveis, como salienta Moura (1992, p.47):

O jogo para ensinar Matemática deve cumprir o papel de auxiliar no ensino do conteúdo, propiciar a aquisição de habilidades, permitir o desenvolvimento operatório do sujeito e, mais, estar perfeitamente localizado no processo que leva a criança do conhecimento primeiro ao conhecimento elaborado.

\section{O mancala}




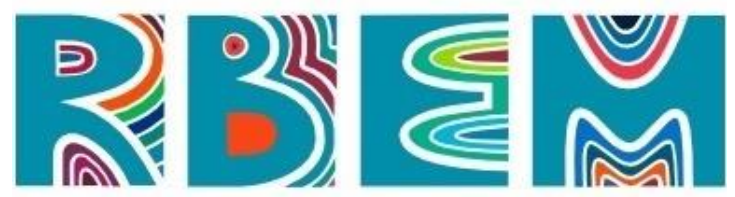

REVISTA BAIANA DE EDUCAÇÃO MATEMÁtICA

Dentro de um universo de diversas possibilidades de jogos com potencialidades didáticas, encontra-se um jogo milenar, jogado em diversas partes do mundo, com inúmeras versões. Trata-se dos jogos da familia Mancala. Segundo Santos (2008, p. 13) "Esses jogos apresentam formas e denominações variadas, de acordo com a região de origem.” Assim, é utilizado o termo família, por se tratar de um conjunto de jogos que têm uma estrutura similar e a mesma dinâmica recorrendo, porém, a diferentes regras. O Mancala é um jogo de origem Africana, de tradição popular, passado de geração em geração por via oral e por isso não se sabe ao certo em que época surgiu a primeira versão, nem a localidade exata onde tal aconteceu.

A escolha de uma versão do jogo Mancala para desenvolver este trabalho pode ser justificada sob dois prismas. Primeiramente, essa escolha vai de encontro com a Lei $n^{\circ}$ 10.639, de 9 de janeiro de 2003, que torna "obrigatório o ensino sobre História e Cultura Afro-Brasileira"(BRASIL, 2003) em escolas de ensino fundamental e médio. Infelizmente a contribuição do continente Africano na história geral e na história da Matemática é pouco abordada em sala de aula, dando a impressão que todas as contribuições do continente se resumem ao Egito antigo, deixando de lado as contribuições de outros países na produção do conhecimento moderno. Em segundo lugar, os constumes de povos antigos africanos são contemplados entre as mecânicas do jogo Mancala no que se refere a semeadura. Segundo Santos (2008) o Mancala é "um jogo com profundas raízes filosóficas", evidenciando também o caráter colaborativo que este jogo traz:

embora o objetivo do jogo seja ganhar, não há como pressuposto a eliminação do adversário. Ao contrário. Ambos são estimulados ao "plantio", mesmo em terras adversárias. E cada qual só pode colher se semear. Nesse jogo, ambos colhem. É um jogo em que não há sorte envolvida. Somente raciocínio lógico e matemático.(Santos, 2008, p. 14)

Do que foi dito salientamos o caráter colaborativo trazido pelo jogo. Apesar deste ter como motivação principal o ato de ganhar, os jogos como o Mancala trazem em sua dinâmica a colaboração entre os participantes. Também é de notar a relação que se pode estabelecer entre a prática do jogo e a resolução de problemas já que, por si só, o jogo traz a problemática de procurar uma estratégia para vencê-lo. O desafio de entender o funcionamento do jogo e de pensar como proceder de acordo com a configuração apresentada num determinado momento 


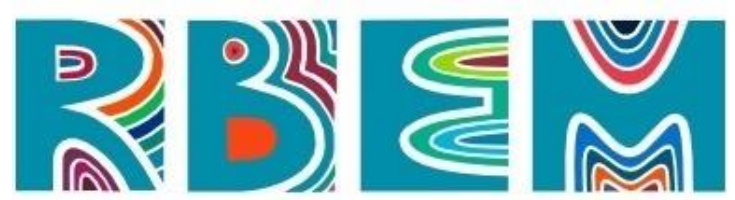

REVISTA BAIANA dE EDUCAÇÃo MATEMÁtICA

podem ser utilizados pelo professor para problematizar situações que conduzem à reflexão sobre a Matemática envolvida, sendo a procura de vitória do aluno um importante fator de motivação.

$\mathrm{O}$ conjunto de regras escolhido para a execução da atividade se assemelham às regras do Mancala Awele (Santos; França, 2017, p. 96) com pequenas variações, visando deixar o jogo mais acessível a todos os alunos e deixá-lo mais dinâmico. As regras do jogo ${ }^{2}$ são descritas a seguir:

- O tabuleiro é formado por doze casas, formando duas fileiras de seis casas cada (Figura 1). Cada fileira pertence a um jogador. Existem, também, dois depósitos, chamados de kallah's, um para cada jogador, sempre localizado à sua direita.

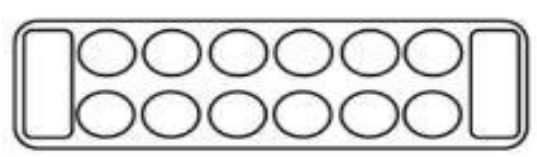

Figura 1: Tabuleiro do Mancala (Amélia, Faria, Afonso, 2012, p. 46)

- Inicialmente, 48 sementes são distribuídas, igualmente em cada uma das 12 casas (Figura 2). Ficando, assim, 4 sementes em cada uma das casas

- Os jogadores decidem quem começa o jogo ${ }^{3}$.

- Cada jogador, na sua vez, deve escolher uma de suas casas, retirar as sementes nela contidas e distribuir uma a uma, no sentido anti-horário, começando na primeira casa à direita da casa escolhida, deixando sementes em sua kallah e nas casas do adversário, até não restar nenhuma (Figura 2). Só não é permitido deixar sementes na kallah do adversário, pulando essa kallah no caso de passar por ela.

\footnotetext{
${ }^{2}$ Extraídas do vídeo "Como jogar MANCALA" https://youtu.be/Sog-iKBh6vs

${ }^{3}$ Podendo recorrer a outro jogo: par ou ímpar.
} 

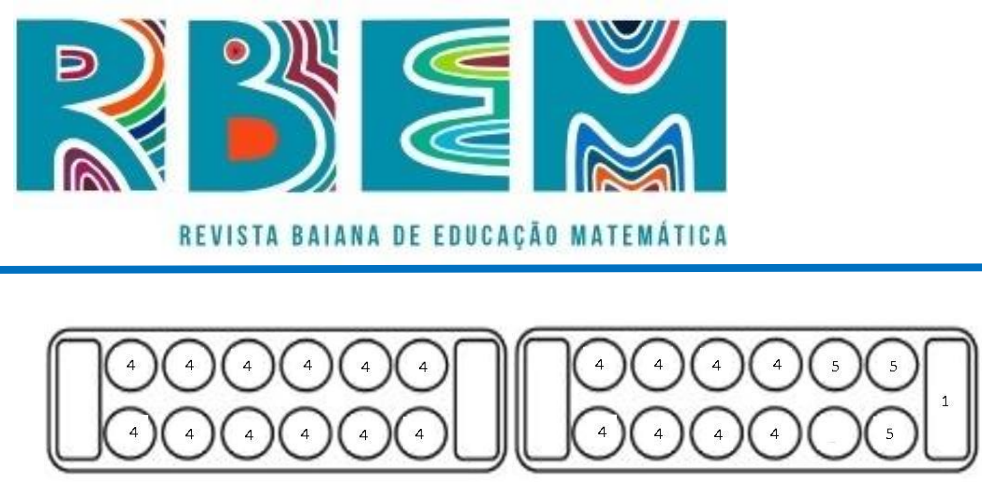

Figura 2: Configuração inicial e exemplo de primeira jogada (Próprio autor)

- Caso a última semente da jogada seja em sua kallah (Figura 3), o jogador tem direito a uma nova jogada, situação que pode ocorrer sucessivas vezes.

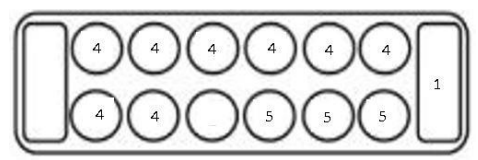

Figura 3: Jogador tem direito a uma jogada extra (Próprio autor)

- Um jogador pode capturar sementes do seu adversário. Isto ocorre se o jogador deixar a última semente de sua jogada em uma de suas casas, que estava vazia. Nesta ocasião, ele pega essa semente e as sementes do seu adversário que estão na casa em frente a esta, levando todas para sua kallah (Figura 4). Porém, fazer a captura não lhe dá direito a uma nova jogada.

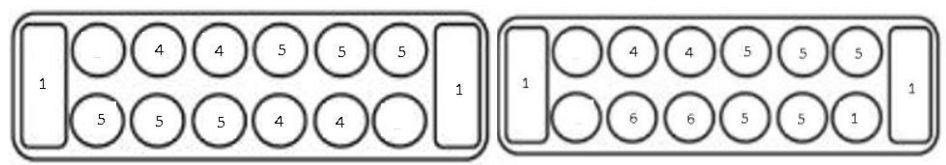

Figura 4: Situação para possível captura de sementes e a captura (Próprio autor)

- Se um dos jogadores ficar sem nenhuma semente em suas casas, o outro jogador deve recolher suas sementes, armazenando-as em sua kallah.

- Ganha o jogo quem primeiro capturar mais da metade das sementes.

\section{Atividade: descrição e discussão de resultados}

Quanto à metodologia esta pesquisa pode ser descrita como exploratória e a análise dos dados obtidos foi efetuada com uma abordagem qualitativa. Foi elaborado um questionário com o objetivo de usar a mecânica do jogo para abordar conceitos matemáticos elementares. 


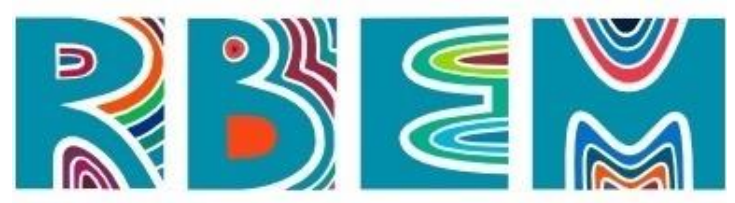

REVISTA BAIANA DE EDUCAÇÃO MATEMÁtICA

A população alvo do estudo foram duas turmas do $7^{\circ}$ ano de uma escola da rede privada de ensino, sendo 25 participantes de uma turma e 7 na outra. A participação dos alunos foi voluntária.

Antes da atividade, decorreram duas etapas de preparação. Na primeira, foi dada uma breve explicação sobre a composição do tabuleiro do jogo (Figura 5), sendo proposto que os alunos construíssem, em duplas, seus próprios tabuleiros feitos com material reciclado.

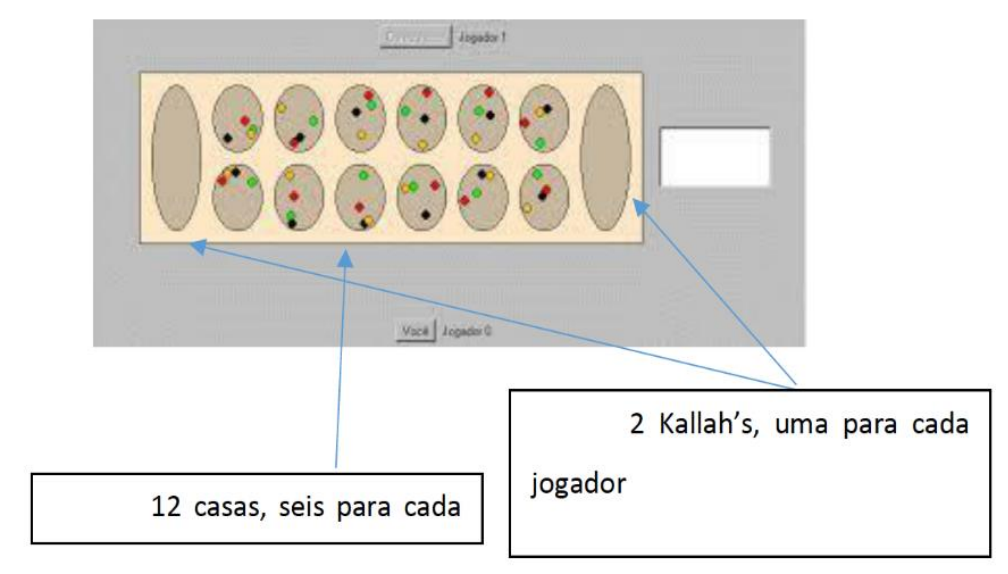

Figura 5: Indicação de tabuleiro fornecida aos alunos (Próprio autor)

Os alunos aderiram a essa proposta com entusiasmo e, com mais ou menos criatividade, produziram seus próprios tabuleiros (Figura 6).
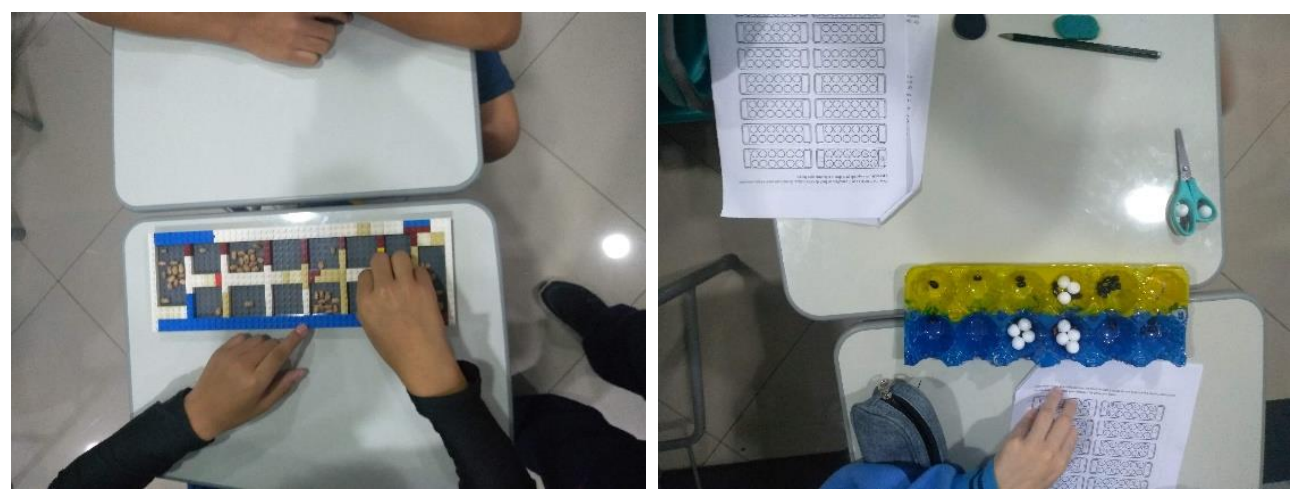

Figura 6: Tabuleiros produzidos pelos alunos (Próprio autor)

Depois, foi indicado um vídeo ${ }^{4}$, para que os alunos se familiarizassem com as regras a ser utilizadas. Na segunda etapa foi feita uma demonstração prática, utilizando um jogo de

\footnotetext{
${ }^{4}$ https://youtu.be/Sog-iKBh6vs
} 


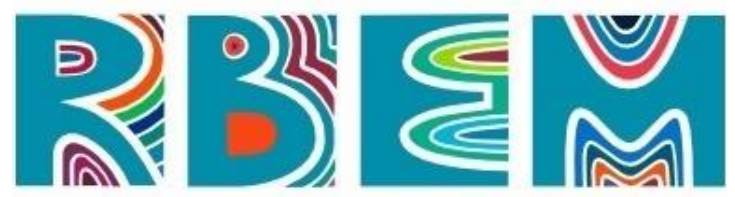

REVISTA BAIANA DE EDUCAÇÃO MATEMÁtICA

Mancala online. ${ }^{5}$ Este jogo pode ser disputado contra o computador (Bot) e tem três níveis de dificuldade crescente: easy(fácil), médium(médio) ou hard(difícil). Outra possibilidade, que não foi utilizada a priori, é baixar o jogo no celular ${ }^{6}$. Para que os alunos visualizassem na prática, algumas regras e vissem como decorria um jogo, o professor exemplificou jogando contra o computador. Seguidamente, foram jogadas algumas partidas entre os alunos.

Após estas duas etapas, foi realizada a atividade que consistia no preenchimento de um questionário sobre procedimentos em situação de jogo, tendo cada dupla o jogo em mãos, que eles mesmo produziram. A atividade foi aplicada na $1^{\text {a }}$ turma no dia 10/06/2019 e na $2^{\text {a }}$ turma nos dias 14/06/2019 e 18/06/2019.

Os dados coletados foram interpretados a partir das respostas dadas pelos alunos segundo os temas Matemáticos implícitos em cada uma das questões. As respostas dadas pelos alunos foram organizadas em tabelas ou de forma descritiva. As respostas foram analisadas buscando compreender os possíveis erros cometidos e interpretar os motivos que originaram o erro.

As duas primeiras questões abordavam o conceito de divisão. Perguntando-se, respectivamente, com quantas sementes começa cada jogador e qual era o número de sementes em cada casa, no início do jogo. 31 alunos responderam corretamente (24 sementes) ao primeiro questionamento, e 1 aluno respondeu 48 sementes, dando uma resposta diferente ao que foi respondido por seu colega de dupla, o que leva a pensar que não leu o enunciado com atenção. No entanto, todos os alunos acertaram o segundo questionamento. Note-se que a resposta a esta questão estava explícita nas regras do jogo e todos estavam com um tabuleiro à disposição. Poderiam ser propostos alguns modos de chegar às respostas corretas. No primeiro caso: dividir o número total de sementes (48) pelos dois jogadores; multiplicar o número de sementes por casa (4) pelo número de casas do jogador (6). Relativamente à segunda pergunta poderiam: dividir o número total de sementes (48) pelo número total de casas (12) ou dividir o número total de sementes de um jogador (24) pelo seu número total de casas (6). Isto mostra o potencial didático do jogo Mancala já para os anos iniciais do Ensino Fundamental.

\footnotetext{
${ }^{5}$ Disponível em https://mancala.playdrift.com.

${ }^{6} \mathrm{https}: / /$ play.google.com/store/apps/details ?id=com.alignit.mancala
} 


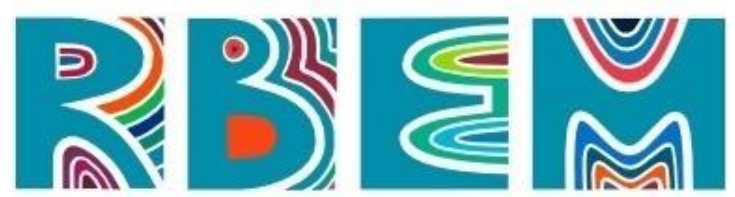

REVISTA BAIANA DE EDUCAÇÃO MATEMÁtICA

A terceira questão diz respeito ao desfecho do jogo. Foi perguntado qual o número mínimo de sementes que um jogador deve ter em sua kallah para garantir a vitória. A resposta correta (25 sementes) foi dada por 18 alunos. Outros dois alunos responderam, mais de 24 sementes, o que poderia ser considerado como uma resposta correta, caso a questão tratasse somente da condição necessária para vencer, porém é questionado qual a condição mínima para vencer. Houve 6 alunos que responderam um número maior que 25. E, 6 alunos responderam um número menor do que 25 , destes, dois alunos deram como resposta 24 , o que leva a pensar que em caso de empate, ambos os jogadores teriam vitória. Muito dessa percepção equivocada pode ter ocorrido pela falta de tempo para que os alunos praticassem mais o jogo. Algumas outras respostas como 4 ou 3, provavelmente devem estar relacionadas com o número inicial de sementes em cada casa.

A pergunta seguinte, abordava a estratégia inicial, perguntando qual a casa que o jogador deve escolher, em sua primeira jogada, para ganhar uma jogada extra. A resposta deveria ser dada no desenho de um tabuleiro apresentado no questionário.

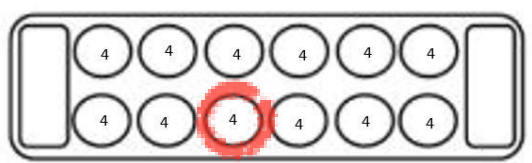

Figura 7: Tabuleiro de Mancala com a indicação da resposta correta da questão 4Fonte: O próprio autor

Complementando esta questão, pedia-se a jogada extra que o aluno efetuaria. Novamente, havia um esquema do tabuleiro para que o aluno indicasse sua resposta com o número de sementes em cada kallah ao final das jogadas. A resposta da primeira parte da questão é fechada (Figura 7): somente um aluno não indicou alguma casa, 30 alunos indicaram a casa correta, dois alunos indicaram uma casa errada, mas deram prosseguimento a jogada. Já a resposta à segunda parte é aberta, possibilitando observar qual seria a estratégia escolhida pelo aluno para o prosseguimento do jogo. $\mathrm{O}$ índice de acertos na primeira parte, revela que a regra que possibilita a obtenção de uma jogada extra foi bem compreendida e, também, qual a atitude que deve ser tomada para que tal ocorra. Isto é, o jogador deve ter, na casa escolhida, um número de sementes igual ao número de casas que deve percorrer até à sua kallah, esta incluída. As respostas à segunda parte da questão revelam ter havido falta de compreensão ao que foi pedido, com muitos alunos sem preencher ou fazendo jogadas 


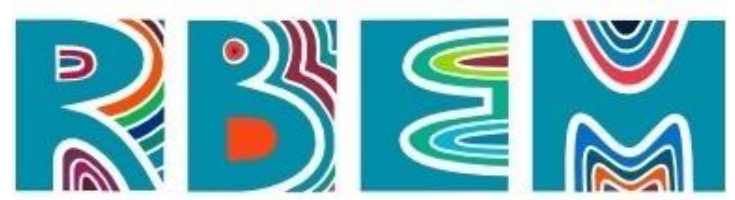

REVISTA BAIANA DE EDUCAÇÃO MATEMÁtICA

incoerentes ao que havia sido feito na jogada anterior. Algumas das jogadas extras escolhidas possibilitaram acumumular mais sementes na kallah ou acumular peças nas suas casas. Em um dos casos, o aluno fez a jogada no sentido horário, podendo o mesmo ter cometido um equívoco em relação às regras ou ter alguma dificuldade relativa a lateralidade, outro assunto que pode ser tratado com este jogo.

$\mathrm{Na}$ quinta questão, perante uma figura do tabuleiro com as casas numeradas de 1 a 6 , os alunos deveriam responder quantas sementes é necessário ter em cada uma dessas casas para, partindo dela, ter direito a uma jogada extra. A resposta poderá ser qualquer número das sequências apresentadas no quadro seguinte:

Tabela 1: Respostas da questão 5

\begin{tabular}{|l|l|l|l|l|l|l|}
\hline Casa $^{\mathrm{o}}$ & 1 & 2 & 3 & 4 & 5 & 6 \\
\hline $\mathrm{n}^{\text {o de sementes }}$ & $6,19,32,45$ & $5,18,31,44$ & $4,17,30,43$ & $3,16,29,42$ & $2,15,28,41$ & $1,14,27,40$ \\
\hline
\end{tabular}

Fonte: Próprio autor

Nenhum aluno indicou todo o conjunto de respostas para cada casa. No entanto, 24 alunos escolheram corretamente o primeiro elemento de cada sequência, mas 8 erraram. Aqui, podem introduzir-se as expressões algébricas, levando o aluno a refletir sobre a variação do número de distâncias e sua relação com a distância da casa à kallah. Outra reflexão que pode ser feita, é relativa à aritmética dos restos, já que os os números presentes em cada sequência são congruentes módulo 13.

A sexta questão coloca a situção inversa à proposta na questão anterior. Agora, é indicado o número de sementes (18) existente em certa casa e, ao escolher esta casa para jogar, consegue-se uma jogada extra. Pergunta-se, então, em que casa estavam as sementes. Ora, 13 é o número mínimo de sementes que é necessário para dar uma volta completa no tabuleiro. A diferença 18 - 13 indica o número de sementes que sobram após uma volta completa. Se considerarmos a kallah como a casa de número 7 , temos $7-5=2$, que nos indica o número da casa pedido. Nesta questão o número de erros (19) foi superior ao de acertos (13). Foi uma questão em que os alunos apresentaram muitas dúvidas e lhes tendo sido dito que simulassem com o jogo, fazendo a jogada de trás para frente. 


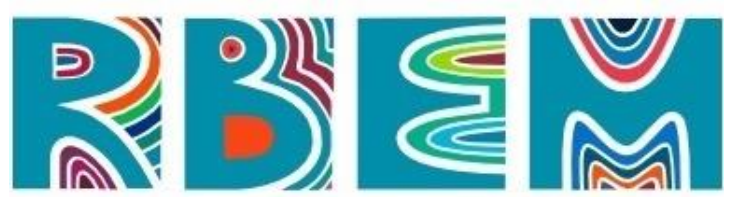

REVISTA BAIANA DE EDUCAÇÃO MATEMÁtICA

$\mathrm{Na}$ sétima questão, foi dada uma configuração de jogo (Figura 8) e perguntado o número máximo de jogadas seguidas que é possível efetuar em sequência. Pedia-se, para indicar qual casa deveria ser escolhida em cada etapa.

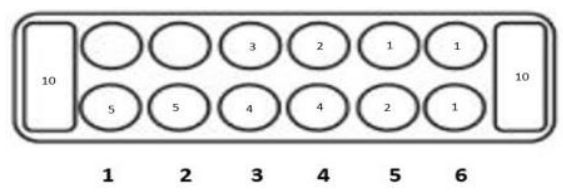

Figura 8: Configuração de jogo (Próprio autor)

Somente os dois alunos, de uma mesma dupla, deram a resposta correta: é possível efetuar 10 jogadas seguidas (casas $6-5-6-3-6-2-6-5-6$ - qualquer casa). Mas, mais da metade dos alunos conseguiu simular mais de 4 jogadas seguidas. $\mathrm{O}$ número mais limitado ocorre pelo fato de que cada escolha interfere na configuração posterior, fazendo ser possível ou não ganhar uma jogada extra.

Houve uma última etapa no questionário, que propunha aos alunos fazerem um jogo, registrando todas as jogadas. Esta etapa não se mostrou proveitosa, deixando os alunos impacientes, pois queriam jogar o jogo livremente, trocar as duplas para desafiar outros alunos e tirar dúvidas que ainda tinham sobre o jogo.

\section{Considerações Finais}

Os jogos, quando aliados a um planejamento eficaz, são um poderoso recurso didático. Essa visão é corroborada tanto pelos documentos oficiais, quanto por pesquisadores que se debruçaram sobre este assunto. O Mancala, de forma específica, tem estrutura e regras que revelam diversas potencialidades didáticas para a aula de Matemática e ainda contribui com a valorização da história Africana em sala de aula mostrando, em sua mecânica, costumes e filosofia de algumas civilizações oriundas deste continente.

A análise de dados gerados pelo questionário permitiu notar que além da variedade de temas que é possível abordar com o Mancala, outros aspetos relativos às inteligências múltiplas podem ser observados, podendo conduzir a diagnósticos sobre o estado de aprendizagem dos alunos sobre esses mesmos temas, bem como a questões relativas à orientação e lateralidade.

A maioria dos alunos ficaram animados com a atividade e participaram de bomgrado, fazendo todas as etapas propostas, preenchendo o questionário e tirando eventuais dúvidas 


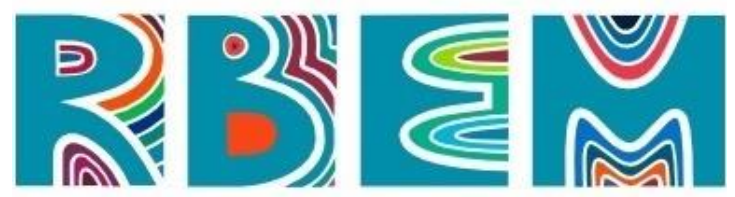

REVISTA BAIANA DE EDUCAÇÃO MATEMÁtICA

sobre as questões ali contidas. Tomou-se o cuidado de sanar dúvidas somente em relação a escrita das questões, sem influenciar nas respostas dos alunos. Ao final do preenchimento os alunos estavam querendo trocar de duplas para que pudessem desafiar outros colegas.

É importante ressaltar que algumas das respostas citadas como certas na questão 5, podem ser absurdas na prática do jogo. Mas essas respostas trazem a possibilidade de propor desafios relacionados ao acúmulo de certo número de sementes em uma dada casa, analisando se é possível ou não que isso ocorra, verificando quantas jogadas seriam necessárias para chegar neste resultado. Falar sobre todo o conjunto de resultados leva à abstração e à criação de conjecturas, possibilitando generalizar o resultado.

Uma outra possibilidade de abordagem pedagógica que permitirá uma discussão entre os alunos e a introdução de conceitos, consiste em sugerir aos alunos que (re)criem o jogo. Mantendo as regras de funcionamento do jogo e o número de sementes, pedir que sejam propostas algumas alterações relativamente à constituição do tabuleiro, número de sementes, discutindo os casos de possibilidade e impossibilidade em consonância com o interesse que o jogo deve despertar. Ou, mantendo a configuração do tabuleiro, sugerir que o número de sementes seja alterado, discutindo a vaibilidade das sugetões dos alunos.

Existem outras potencialidades didáticas que emergem do uso do Mancala, desejandose continuar explorando estas potencialidades, abordando outros temas e diversificando o grau de dificuldade das questões.

\section{Referências}

BARRETO, G. B. B; FREITAS, A. M. T. Jogos educativos africanos da família mancala: um caminho para ensinar e aprender matemática. Laplage em Revista, Sorocaba, v. 2, n. 1, p. 146-153, 2016.

BOALER, J. Mente sem barreiras: as chaves para destravar seu potencial ilimitado de aprendizagem. Porto Alegre: Penso, 2020.

BRASIL. Base Nacional Comum Curricular - BNCC. Brasilia: MEC. 2018.

BRASIL, Lei no 10639 de 9 de janeiro de 2003. Ministério da Educação. Diretrizes Curriculares Nacionais para a Educação das Relações Étnicos Raciais e para o Ensino de História e Cultura Afro-Brasileira e Africana. MEC/SECAD. 2005. 


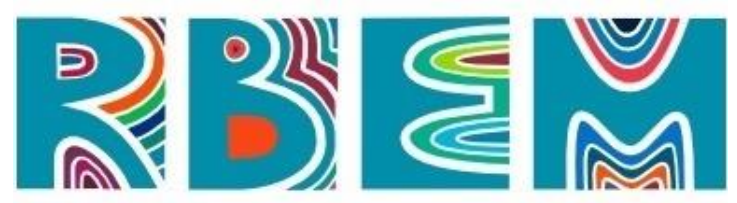

REVISTA BAIANA DE EDUCAÇÃO MATEMÁTICA

BRASIL. Parâmetros Curriculares Nacionais, Terceiro e Quarto Ciclos do Ensino Fundamental, Matemática. Brasilia: MEC/SEF, 1998

MALFATO, I. C. Jogos Africanos: alternativa metodológica para o desenvolvimento do raciocínio lógico e propagação desta cultura. O professor PDE e os desafios da escola pública paranaense, Universidade Estadual do Oeste do Paraná, Toledo, 2012.

MOURA, M. O. O Jogo e a Construção do Conhecimento Matemático. Série Idéias, São Paulo, n. 10, p. 45-52, 1992. Disponível em: <

http://www.crmariocovas.sp.gov.br/pdf/ideias_10_p045-053_c.pdf >. Acesso em: 10 de dezembro de 2020

SANTOS, C. J. Jogos africanos e a educação matemática: semeando com a família mancala. Universidade Estadual do Paraná, Maringá, 2008.

SANTOS, E. C.; FRANCCA, M. C. S. Simbiose entre Etnomatemática e a cultura AfricanaJogo Mancala Awelé em sala de aula. Com a Palavra o Professor, Vitória da Conquista, v. 1, n. 1, p. 89-100, 2017.

SOUZA, C. H. S. Potencialidades didáticas do uso do mancala no $7^{\circ}$ ano do ensino fundamental. 2019. 50f. Monografia (Especialização em Educação Matemática) - Pró-Reitoria de Pós-Graduação, Pesquisa, Extensão e Cultura, Colégio Pedro II, Rio de Janeiro, 2019.

Artigo submetido em: 05/11/2020

Artigo aceito em: 15/12/2020 